\title{
Whole Person, Whole Journey: Developing a Person-Centred Regional Dementia Strategy
}

\author{
Paul Stolee, Jessica Ashbourne, Jacobi Elliott, Sarah Main, Nicole Holland, Cole Edick, \\ Courtney Ropp, Catherine Tong, $\odot$ and Sheila Bodemer \\ School of Public Health and Health Systems, University of Waterloo, Waterloo, Ontario
}

\begin{abstract}
RÉSUMÉ
Nous présentons le développement d'une stratégie régionale en matière de démence au sud-ouest de l'Ontario (Canada). Des collaborations rassemblant des parties prenantes d'une autorité de santé régionale ont permis d'élaborer une stratégie en matière de démence. Des entretiens ont été menés avec des personnes atteintes de démence et leurs proches soignants $(n=26)$, ainsi qu'avec des administrateurs de soins de santé et des décideurs politiques $(n=33)$. Une enquête sur la définition des priorités a aussi été réalisée $(n=64)$. Les deux groupes de participants ont identifié la compassion, le professionnalisme et les soins prodigués par les prestataires de soins aux premiers stades de la démence comme étant les points forts du système. Les deux groupes ont également souligné la nécessité d'une intégration et d'une coordination accrues, de soins davantage axés sur la personne, d'un soutien aux proches soignants et d'une plus grande souplesse dans la prestation et la réception des services. Les priorités les plus reconnues étaient les suivantes : améliorer le soutien aux proches soignants, l'accès aux soins et leur qualité à l'échelle du système. Ces forces, besoins et priorités ont été intégrés dans un cadre stratégique intitulé "Whole Person, Whole Journey". Les organisations œuvrant sur des stratégies en matière de démence pourront utiliser ce modèle comme tremplin pour leurs propres activités.
\end{abstract}

\begin{abstract}
We present the development of a regional dementia strategy in Southwestern Ontario, Canada. We worked with stakeholders in a regional health authority to develop a dementia strategy. We conducted interviews with persons with dementia and their care partners $(n=26)$ and health care administrators and policy makers $(n=33)$; and administered a priority-setting survey $(n=64)$. Both participant groups identified provider compassion, professionalism, and care in the early stages of dementia as system strengths. Both groups also highlighted a need for more integration and coordination, a need for more person-centred care, support for care partners, and more flexibility in the provision and receipt of services. The highest-ranked priorities were improving care partner support, improving access to care, and improving system-wide quality. We integrate these strengths, needs, and priorities in a strategic framework, "Whole Person, Whole Journey". Organizations developing a dementia strategy may use this framework as a springboard for their own work.
\end{abstract}

We thank the members of the Project Advisory Group (Dr. Michael Borrie, Dr. Lisa van Bussel, Jennifer Speziale, and Elizabeth McCarthy) and research participants. We also acknowledge the contributions of research team members, Miranda McDermott and Heather McNeil. This project was funded by a grant from the South West Local Health Integration Network Behavioural Supports Ontario.

Manuscript received: / manuscrit reçu : 07/01/2019

Manuscript accepted: / manuscrit accepté : 08/04/2020

Mots-clés : vieillissement, stratégie en matière de démence, personnes atteintes de démence, partenaires de soins, recherche qualitative, entretiens en dyade, enquête sur les priorités

Keywords: aging, dementia strategy, persons with dementia, care partners, qualitative research, dyad interviews, priority survey La correspondance et les demandes de tirés-à-part doivent être adressées à : / Correspondence and requests for offprints should be sent to:

Paul Stolee, Ph.D.

School of Public Health and Health Systems University of Waterloo

200 University Avenue West

Waterloo ON, N2L 3G1 Canada

(stolee@uwaterloo.ca)

Canadian Journal on Aging / La Revue canadienne du vieillissement 40 (3) : 436-450 (2021)

(C) Canadian Association on Gerontology 2020. This is an Open Access article, distributed under the terms of the Creative Commons Attribution licence (http://creativecommons.org/licenses/by/4.0/), which permits unrestricted re-use, distribution, and reproduction in any medium, provided the original work is properly cited.

doi:10.1017/S071498082000015X 


\section{Introduction}

Canada, like many countries, is facing a rapid increase in the number of persons living with dementia. At present, there are more than 400,000 older Canadians living with dementia, with nearly 80,000 new cases diagnosed each year (Government of Canada, 2019). By 2038, direct care costs are expected to rise from $\$ 15$ billion to $\$ 153$ billion dollars annually (Alzheimer Society of Canada, 2010). These figures catalyzed the development of a National Dementia Research and Prevention Plan (Rockwood \& Keren, 2010), as well as efforts to develop strategies to guide a coordinated response to dementia. Dementia strategies are created to "help governments ensure that health and social care systems are adequately structured and funded to ensure high-quality care and support is available to people living with dementia" (Pot \& Petrea, 2013 , p. 5). National dementia strategies have proliferated (Edick, Holland, Ashbourne, Elliott, \& Stolee, 2017; Fortinsky \& Downs, 2014), with more than 30 countries having adopted a national action plan (Guillette et al., 2018). The World Health Organization strongly endorses the concept of dementia strategies, as part of its Global Action Plan on the Public Health Response to Dementia (World Health Organization, 2017).

Provincial efforts across Canada are inconsistent: five provinces (Nova Scotia, Quebec, Ontario, Alberta, and British Columbia) have dementia strategies, whereas others, such as New Brunswick, are developing seniors strategies that will have dementia embedded (Alzheimer Society of Canada, 2019). We conducted our research in Ontario, which in 1999 was the first province to develop and adopt a dementia strategy (Canadian Academy of Health Sciences, 2019). Ontario introduced a second provincial dementia strategy in 2017 (Alzheimer Society of Canada, 2018b), and Canada launched its first national strategy in 2019 (Government of Canada, 2019).

Although there is a need for a strategic response to dementia (Alzheimer Society of Canada, 2010; World Health Organization, 2017), a one-size-fits-all strategy will not be adequate to address the unique needs of the populations within each jurisdiction, and regions within those jurisdictions. Internationally, countries and health regions have been working to develop their own regionspecific dementia strategies (Burns, 2010). These strategies are often available in the grey literature (Dewing \& Dijk, 2016), and not necessarily in peer-reviewed journals, limiting the potential sharing of lessons learned. Furthermore, different levels of dementia strategies serve distinct purposes. Within the realm of dementia strategies and action plans, there is a place and role for those at the national, provincial, regional, and organizational level (Guillette et al., 2018). Whereas a national dementia strategy is positioned to work on issues such as public awareness campaigns, funding research, and guiding education policy (Guillette et al., 2018), regional strategies will be more focused on issues related to local programming and service delivery.

Regional dementia strategies must be rooted in the local context and the specific needs of the unique populations that they serve (Canadian Academy of Health Sciences, 2019). This focus on unique regional populations is important, as many national and international plans have not taken into consideration the needs of specific groups, including Indigenous persons, rural populations, linguistic minorities, and persons with intellectual disabilities (Guillette et al., 2018). In Canada, only the Manitoba and Alberta plans explicitly consulted with and focused on the needs of rural populations and their access to care (Guillette et al., 2018). Morgan (2018), Morgan et al. (2011), Morgan, Innes, and Kosteniuk (2011), and Constantinescu, Li, Yu, Hoggard, and Holroyd-Leduc (2018) have emphasized the need for stronger dementia care in rural and remote communities in Canada. In this article, we present the development of a regional dementia strategy for a regional health authority - the South West Local Health Integration Network (SW LHIN) - which includes both urban and rural areas in Ontario.

Many factors, such as stage and type of diagnosis, or the personal and system context, can influence the dementia journey, making it a highly individualized experience (Steelman, De Casterlé, Godderis, \& Grypdonck, 2006). In the process of developing and implementing a dementia strategy, it is important to understand that the dementia experience is more than the presentation of symptoms. Across Canada, regions developing dementia strategies have recognized, almost unanimously, that persons with dementia and their care partners must be consulted in this process (Canadian Academy of Health Sciences, 2019).

Peer-reviewed literature on the development of regional and provincial dementia strategies, however, is scarce (Edick et al., 2017). Most peer-reviewed manuscripts have focused on the content of dementia strategies, rather than on the processes used to inform them (e.g., Edick et al., 2017; Fortinsky \& Downs, 2014; Nakanishi et al., 2015). As Guillette et al. (2018) note in their literature review "we did not find scientific articles on actors who participated in drafting provincial action plans, except for a brief outline of the situation in Quebec" (p., 27).

In this article, we present the development of a regional dementia strategy in Southwestern Ontario, and we share the processes used to engage with a range of stakeholders. We focused on the lived experiences and perspectives of key stakeholders, including persons with dementia and their care partners. With a focus 
on both the person with dementia and the care partner, our work is both "person-centred" and "patient- and family-centered" (Johnson, Abraham, \& Shelton, 2009).

\section{Methods}

Our research team, The Geriatric Health Systems Research Group, worked with stakeholders in the SW LHIN to develop a dementia strategy for their region. This mixed-method, multi-component study draws on a range of qualitative approaches (Creswell, 2007). We utilized a combination of an environmental scan, surveys, and interviews. Our work included a review of existing provincial, national, and international dementia strategies (Edick et al., 2017) and an environmental scan to understand the current state of dementia in the SW LHIN (Geriatric Health Systems Research Group, 2016); the development of community advisory groups; in-depth interviews with a variety of stakeholders; and a priority- setting survey. Our work is grounded in the perspectives and opinions of persons with dementia, and as such, our approach to this study was also guided by the growing body of literature on patient engagement (Domecq et al., 2014) and patient-oriented research (Canadian Institutes of Health Research, 2016a). Collectively, this research led to the development of a regional dementia strategy, and a framework titled "Whole Person, Whole Journey." In this article, we focus on the stakeholder-driven results from the interviews and priority-setting survey and the resultant framework.

\section{Setting and Context}

The SW LHIN is the regional health network responsible for care provision in a $21,639 \mathrm{~km}^{2}$ region, serving nearly $1,000,000$ residents (South West Local Health Integration Network, 2018). We developed a project advisory group (PAG) (with four health care leaders from the LHIN) and a community consultation advisory group (CCAG) (with 51 representatives from local agencies and service providers) to help guide this research project. These advisory groups consisted of health care providers and administrators from throughout the SW LHIN, but did not include persons with dementia or care partners. Through regular meetings and e-mail, both advisory groups assisted with study design, recruitment, survey and interview guide development, and review of preliminary findings, via plain language reports. This study received ethics clearance from the University of Waterloo Office of Research Ethics. We were especially mindful of acquiring informed consent from persons with dementia, and where appropriate, obtaining consent from care partners (Kim, 2011). Our consent forms clearly outlined a participant's right to withdraw at any time, and noted that all interviews would take place in a private and confidential setting of the participant's choosing.

\section{Recruitment}

We worked with the PAG and CCAG to develop our recruitment strategy, which was purposive and further detailed subsequently. The recommendations made by these groups supported: (1) a holistic perspective of the dementia journey (including different types and stages of dementia), (2) a broad community perspective of dementia care, and (3) a consultation process that was as representative as possible of the local health care system and population. In an effort to be representative, we purposively recruited persons living with different types and stages of dementia, participants living/working in both urban and rural settings, and participants with dementia concurrently living with disabilities.

Six local chapters of the Alzheimer Society aided in the recruitment of persons living with dementia and their care partners. Eligible participants were persons who were (1) diagnosed with, or cared for someone who has been diagnosed with, a dementia and (2) connected with the Alzheimer Society/Outreach Service. After initial contact with the Alzheimer Society, we followed up with a letter of information. Informed consent was provided by each participant; where required, consent was provided by care partners (Kim, 2011). The PAG and CCAG recruited the health care providers and administrators. We continued recruitment until we reached theoretical saturation (Morse, 2015) from all participant groups; meaning that data were both comprehensive in scope and that data from a range of participants had essential characteristics in common (Morse, 2015). Processes for determining saturation are outlined in the data analysis section.

\section{Participant Characteristics}

We conducted semi-structured interviews with care partners $(n=14)$, and six dyads $(n=12,6$ persons with dementia and 6 care partners), for a total of 26 participants. We also completed interviews with 33 participants from the health care system. Participant characteristics are summarized in Table 1. All participants were able to complete an interview in English, which is largely reflective of the region in which we were working (City of London, 2019). The SW LHIN has separate initiatives to support Indigenous and French-speaking citizens (SW LHIN, 2019). A dementia strategy for urban Ontario (e.g., the ethnically diverse Greater Toronto Area) would require a more linguistically inclusive approach to data collection. No participants withdrew from the study.

\section{Data Collection: Interviews}

Our data collection team was led by two Ph.D.-trained interviewers with extensive experience ( $\geq 30$ years, and $\geq 7$ years) conducting qualitative research, prior 
Table 1: Interview participants summary

\begin{tabular}{|c|c|c|c|}
\hline \multicolumn{4}{|c|}{ Person with Dementia $(n=6)$} \\
\hline Demographics & Types of Dementia & Care Partner $(n=20)$ & Health Care System ( $n=33)$ \\
\hline $\begin{array}{l}\text { - Primarily male } \\
\text { - Age range: } 59-94 \\
\text { - Majority age } \\
\text { range: } 75-84\end{array}$ & $\begin{array}{l}\text { - Many reported no specific diagnosis apart from } \\
\text { dementia } \\
\text { - For those reporting a diagnosis, equal represen- } \\
\text { tation of: } \\
{ }^{\circ} \text { Alzheimer's disease } \\
{ }^{\circ} \text { Vascular dementia } \\
{ }^{\circ} \text { Mild cognitive Impairment } \\
\text { - Fronto-temporal dementia was present in all cases } \\
\text { of mixed dementia. The mixed dementias that were } \\
\text { mentioned included: Alzheimer's disease, vascular } \\
\text { dementia and fronto-temporal dementia and Alz- } \\
\text { heimer's disease and fronto-temporal dementia }\end{array}$ & $\begin{array}{l}\text { - Primarily female } \\
\text { - On average } 10 \text { years } \\
\text { younger than person } \\
\text { with dementia } \\
\text { - Age range: } 56-80 \\
\text { - Majority age range: } \\
65-74 \\
\text { - Care partner rela- } \\
\text { tionships: } \\
\text { 'Primarily spousal } \\
\text { (wives) } \\
\text {-4 filial care partners }\end{array}$ & $\begin{array}{l}\text { - Policy makers } \\
\text { - Health care providers } \\
\text { - Administrators from } 6 \text { counties } \\
\text { - Represent several sectors (family health } \\
\text { teams, behavioural health services, long-term } \\
\text { care, memory clinics, the SW LHIN, and } \\
\text { several community-based organizations) } \\
\text { - } 3 \text { men, } 30 \text { women }\end{array}$ \\
\hline
\end{tabular}

experience interviewing individuals with dementia, and with a deep understanding of the local health care system. Both had previously worked as formal evaluators within the local health care system, with a focus on geriatrics and care for older adults. These two lead interviewers were accompanied by masters and undergraduate-level research assistants, who served as note-takers during the interviews. Each interview had one lead interviewer and one note-taker. Note-takers used a consistent field note template (Emerson, Fretz, \& Shaw, 2011), in which they were asked to record details about data collection (e.g., length, setting, who participated, tone), begin a preliminary analysis (e.g., noting key words, high-level themes, powerful quotes) and reflect on the data collection process (e.g., what questions worked well, issues or concerns with data collection). The lead interviewers and note-takers verbally "debriefed" after each interview (Emerson et al., 2011), and notes from these discussions were added to the field notes. Note-takers were instructed to type up their notes within 24 hours of the interview, and all field notes were added to the data analysis files (detailed subsequently).

For persons living with dementia and their care partners, the interview objective was to gain the perspectives of those with lived experience in the dementia care system, specifically perceived system strengths and weaknesses. Members of our research team travelled throughout the South West region to complete in-depth interviews in participants' homes. In the interviews with care providers and administrators, we sought to understand the role of service providers and administrators in dementia care, perceived system strengths and gaps, and suggestions for improving dementia care. Sample interview questions are included in Table 2, and the interview guides were developed in consultation with the PAG and CCAG. Both the PAG and CCAG reviewed draft interviews, made revisions and suggested specific areas of inquiry/questions.
Interviews with participants from the health care system lasted an average of 32 minutes (min: 11, max: 77), and were either completed in private offices or over the telephone. Interviews with care partners and persons with dementia lasted an average of 57 minutes ( $\min : 37$, max: 93). Interviews were digitally recorded and transcribed. No participants requested a non-recorded interview, and consistent with our consent forms and ethics application, all identifying information (e.g., the names of individuals, clinics, organizations) was removed from the transcripts as they were transcribed. The students who assisted with data collection were trained by the lead interviewers to complete the transcriptions. All transcriptions were randomly spot-checked by another team member (i.e., another student), comparing and contrasting the typed transcription with the audio recording.

\section{Data Analysis: Interviews}

We used QSR NVivo 10 software (www. qsrinternational.com) to aid in our analysis of the interviews, simultaneous to data collection. We analysed the transcripts from each informant group separately, which allowed us to compare the system strengths and weaknesses identified by each group. We employed emergent thematic analysis (Bradley, Curry, \& Devers, 2007), and this consisted of two phases: initial and focused coding. During initial coding, the lead interviewers and note-takers read the transcripts line by line to determine initial codes (Saldaña, 2016) for each informant group. We also used regular team meetings and team field notes during data collection to reflect on recurrent and dominant interview themes, with features in common across different sets of participants (Morse, 2015), to determine the point at which we believed theoretical saturation had been reached (Morse, 2015).

Field notes were uploaded in NVivo, and these preliminary notes assisted with the initial identification of 
Table 2: Sample interview guide questions

Interview Guide Questions: Care Partners and Persons with Dementia

Can you please tell me about the services, support and care that you have received since you have been diagnosed with dementia? (probes: community supports, specialist care)

Can you tell me about any experiences that you've had within the health care system that have gone particularly well?

a. What was it that made this experience so positive?

b. Who was involved? What did they do to make the experience positive?

Can you tell me about any experiences that you've had with the health care system that did not go so well?

a. What was it that made these experiences negative?

b. What could have been done to improve your experiences

Do you think that having dementia (or the person you care for having dementia) has influenced your health care system experiences? How do you think it differs from health care of those without dementia?

What do you think can be done to make the wider community, things that are outside of the health care system, more supportive of people with dementia?

\section{Interview Guide Questions: Health Care Providers}

Can you tell me about your role (and the role of your organization/program) in the care for persons with dementia?

What do you feel is currently being done particularly well in the way that care/support is provided to persons with dementia and their caregivers as they move throughout the health care system?

What do you think could be done to improve the care of persons with dementia and their caregivers as they move throughout the health care system? Are there any gaps in the current system of dementia care? If yes, what are they?

What do you think could be done to make the wider community (i.e., beyond the health care system) more supportive of persons with dementia and their caregivers)?

codes. Our entire research team, including the lead interviewers, student note-takers/transcribers, and several graduate-level research assistants, contributed to the analysis after the initial coding. To facilitate this team-based approach to data analysis (Guest \& MacQueen, 2008), we held a 1-day in-person analysis workshop. Prior to the workshop, all team members were assigned three transcripts to read, and were asked to review the initial coding in NVivo. The workshop team included four undergraduate and co-op students, four Master's level students/staff, an administrative assistant, and one Ph.D. student, and was led by two Ph.D.trained qualitative health researchers.

In the analysis workshop, we printed off anonymized data excerpts from each transcript and all of the codes. We collectively then clustered these codes and quotes into what we viewed as higher-level themes, and discussed and debated this clustering activity. After clustering the codes into high-level themes, we worked together to identify names for each theme. This naming activity combined our familiarity with the dementia strategies literature (Edick et al., 2017) and the verbatim quotes themselves. In the workshop we also created a working definition for each higher-level theme, to assist with our interpretation and further coding. After the workshop, the lead interviewers and note-takers then revisited the data in NVivo to organize the coding nodes into our agreed upon themes.
Interviewers also engaged in memoing (Charmaz, 2015) and reflexivity (Patton, 2002), ensuring that the analysis remained true to participant voices; specifically, we compared and contrasted our theme names and definitions with verbatim quotes to ensure our faithful representation of the data. The language that we use in our themes is consistent with that used in the interviews, and reflective of our familiarity with the global dementia strategy literature. We provide an overview of the analysis process, from initial codes, to themes, descriptions, and framework placement, in Table 3.

\section{Data Collection: Priority-Setting Survey}

After the interviews, we also used a priority-setting survey to validate what we heard in the interviews, and to help us articulate a clear set of priorities for the SW LHIN in the dementia strategy. We compared the high-level themes that emerged from the interviews with themes that were identified in our review of existing dementia strategies (Edick et al., 2017). Repetitions or similar themes were combined, and this resulted in a list of 13 potential priority objectives for inclusion in the dementia strategy. The lead interviewers and notetakers developed this list of priority objectives, and it was also shared with the PAG and CCAG to ensure that the language and concepts would resonate with the intended respondents. We included these 13 priorities 
Table 3: Data synthesis: From initial codes to framework

\begin{tabular}{|c|c|c|c|c|}
\hline Initial Code(s) & Theme & Description $^{a}$ & Example Quote ${ }^{a}$ & Placement in Framework \\
\hline $\begin{array}{l}\text { Caregiver: } \\
\text { - Stresses } \\
\text { - Programs/ } \\
\text { Supports } \\
\text { - Burnout } \\
\text { - Roles } \\
\text { - Own health }\end{array}$ & $\begin{array}{l}\text { Caregiver } \\
\text { Support }\end{array}$ & $\begin{array}{l}\text { Caregivers experience a long and } \\
\text { stressful journey, and many of } \\
\text { them experience burnout. Their } \\
\text { needs are varied and can } \\
\text { change as they assist the indi- } \\
\text { vidual with dementia along the } \\
\text { continuum, requiring different } \\
\text { supports at different stages. }\end{array}$ & $\begin{array}{l}\text { "As a caregiver, I concentrate on } \\
\text { her. I don't think about me. And } \\
\text { I think it was one of my doctors } \\
\text { who said, 'We know what her } \\
\text { concern is, now we have to } \\
\text { concentrate on you."' } \\
\text { (Caregiver) }\end{array}$ & $\begin{array}{l}\text { All individuals involved in care are } \\
\text { placed at the centre of our } \\
\text { framework, with figures repre- } \\
\text { senting providers, persons with } \\
\text { dementia, and caregivers. }\end{array}$ \\
\hline $\begin{array}{l}\text { - Education for providers } \\
\text { on dementia } \\
\text { - Education for judicial } \\
\text { system/police on } \\
\text { dementia } \\
\text { - Reduce stigma in public } \\
\text { - Education \& supports } \\
\text { for family }\end{array}$ & $\begin{array}{l}\text { Awareness and } \\
\text { education }\end{array}$ & $\begin{array}{l}\text { There is a need for more educa- } \\
\text { tion to reduce the stigma and } \\
\text { improve the quality of care with } \\
\text { partners within and external to } \\
\text { their immediate circle of care. }\end{array}$ & $\begin{array}{l}\text { "Educating the public and taking } \\
\text { the stigma away from the word } \\
\text { 'dementia'; and making people } \\
\text { less afraid to use the term and } \\
\text { discuss it." (Family physician) } \\
\text { "Training in universities. There } \\
\text { needs to be more education } \\
\text { around dementia... there's a } \\
\text { little blip mentioned in the text- } \\
\text { book around seniors and } \\
\text { dementia." (Social worker) }\end{array}$ & $\begin{array}{l}\text { We perceive education, aware- } \\
\text { ness, and the reduction of } \\
\text { stigma to be drivers of demen- } \\
\text { tia care, and as such are placed } \\
\text { along with other drivers (e.g., } \\
\text { research, technology) within the } \\
\text { framework. }\end{array}$ \\
\hline
\end{tabular}

Note. ${ }^{a}$ We have detailed themes, descriptions, and example quotes for the entire data set, available upon request.

in an online priority-setting survey (see supplementary material). We distributed the survey, via e-mail, to interview participants (including health care providers, persons living dementia, and care partners) and members of our project advisory boards. In total, 52 providers/administrators and 12 persons with dementia/ care partners completed the survey. All 64 participants were asked to rate each priority on a scale of 1-10, with $1=$ Not important at all and $10=$ Extremely important. Health care providers and administrators were also asked to rate the priorities in terms of their expected impact (scale of 1-10) and ideal time frame for implementation. The expected impact and ideal time frame results are not reported here, but are available upon request. The ranked priorities, associated outcomes, and time frames were included in our full report to the leadership of the SW LHIN (Geriatric Health Systems Research Group, 2016).

\section{Data Analysis: Priority-Setting Survey}

We conducted the priority setting survey online (fluidsurvey.com). The results were then downloaded into a spreadsheet; descriptive statistics were calculated in Excel and SPSS (version 22.0) to rank the priorities from each informant group. Standard deviations for each rating were small (1.3-2.0), indicating consensus (von der Gracht, 2012); standard deviations are not reported.

\section{Data Synthesis: Framework Development}

Upon completion of data collection and preliminary analysis, our team engaged in a 1-day data synthesis forum; this included the same members who participated in the team-based analysis workshop. In the development of this framework, we employed several of the heuristics recommended by Jaccard and Jacoby (2010), including (1) thinking visually about the data (e.g., we mapped and graphed data elements of the model with post-its, printed themes and definitions, whiteboards, and chart paper); (2) discussing what pushed our "hot buttons" and examining our emotions (e.g., talking about the themes, quotes, and elements that made us feel passionate, upset, or moved to take action); (3) collectively applying the "what" and "why" questions to our framework (e.g., continually pushing one another to justify our changes to the emerging framework); and (4) trying to fit our data onto existing social science theories (e.g., we tried to see if our data fit into a modified socio-ecological model (Bronfenbrenner, 1977)). We also compared and contrasted the concepts in our framework to our literature review on existing global dementia strategies (Jaccard \& Jacoby, 2010).

Through these team discussions, data reviews, and brainstorming sessions, we synthesized the results into a single image and strategic framework, titled "Whole Person, Whole Journey" (see Figure 1). The intent of this strategic framework is to consolidate our recommendations for a holistic and person-centred approach to dementia care within the SW LHIN. The elements of the framework, and their relationships to one another, are detailed subsequently. We then shared the framework and sample quotes with the PAG and CCAG. We circulated the framework via e-mail to all members of both groups, and discussed the framework at an 


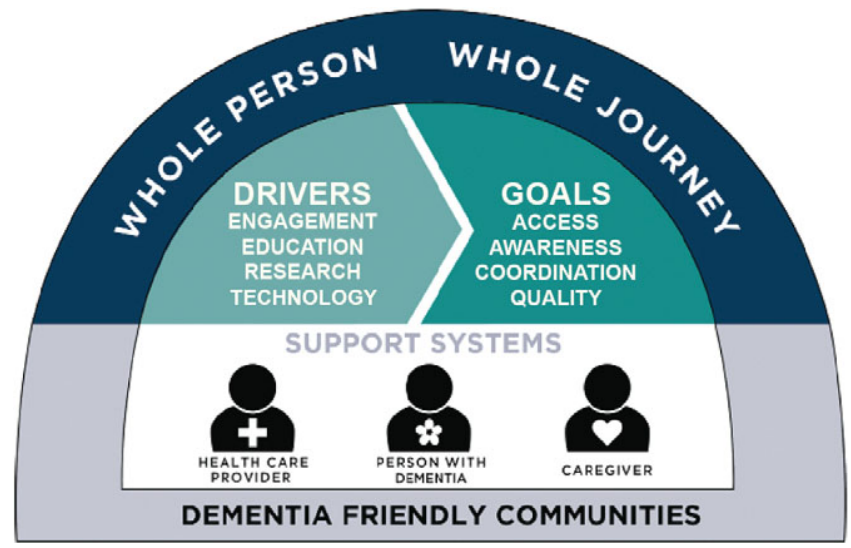

Figure 1: Strategic Framework: Whole Person, Whole Journey

in-person meeting with each group. Both the PAG and CCAG endorsed the framework; neither group requested any changes.

\section{Strategies for Rigour and Knowledge Translation}

We employed several techniques to ensure methodological rigour, including the recording of decisions made throughout data collection and analysis, peer debriefing among members of the research team, and memo writing (Cutcliffe \& McKenna, 2004; Richards \& Morse, 2007). Also, we regularly shared draft data collection tools, preliminary findings, and drafts of the dementia strategy with members of the PAG and CCAG. The findings resonated (Tracy, 2010) with these stakeholders. Finally, we shared the findings of this research both with the SW LHIN and other stakeholders in the region (e.g., local chapters of the Alzheimer's Society, local memory clinics). We provided a copy of the dementia strategy to the LHIN for review. We also hosted a presentation and roundtable discussion of the strategy and our findings at an annual meeting focused on geriatric care with more than 150 providers; again, findings, which are further detailed, resonated with attendees.

\section{Results}

In this section, we present: the system strengths and system gaps/needs identified in the interviews, the priorities that were identified and then ranked by participants, and the final dementia strategy framework. We share additional verbatim quotes to support these sections in Tables 4 and 5 .

\section{System Strengths}

Persons with dementia and their care partners identified three system strengths, and providers, administrators, and policy makers identified five (see Table 4).
These participants highlighted the professionalism and compassion that persons with dementia receive from care providers.

\section{System Gaps and Needs}

Persons with dementia and their care partners identified five areas of concern within the local health care system; representatives from the health care sector identified six (see Table 4). Both groups, persons with dementia and their carers and care providers, highlighted a need for more integration and coordination, a need for more person-centred care, support for care partners, and more flexibility in the provision of services. Participants in rural areas cited gaps in the availability and accessibility of local programs and supports, transportation issues, and the need for more specialized care in non-urban settings.

\section{Priorities}

Themes from interviews were used to create a list of 13 priorities (see Table 6). Participants were asked to rate these priorities in terms of their expected impact, on a scale of 1-10. Overall, all 13 priorities were rated high, with the lowest average ranking being 7.92/10.

Of the 13 priorities, both participant groups had one highly ranked priority in common: "improving quality across the system of dementia care". Providers identified "support for care partners" as the top priority, whereas persons with dementia and their care partners ranked "care coordination and system navigation" highest. We believe that providers' emphasis on "support for care partners" is in part because of their clinical observations and experiences, and the fact that care partners themselves may be less likely to express their own need for supports, which is well documented in the literature (Silva, Teixeira, Teixeira, \& Freitas, 2013). Persons with dementia and their care partners highlighted the need to educate the workforce (9.50), 
Table 4: System strengths

\begin{tabular}{|c|c|c|}
\hline \multicolumn{3}{|c|}{ Strengths Identified by Persons with Dementia and their Care Partners } \\
\hline Strengths & Description & Verbatim Examples \\
\hline $\begin{array}{l}\text { Care in the early } \\
\text { stages of dementia }\end{array}$ & $\begin{array}{l}\text { People at the earlier stages of dementia more often cited positive } \\
\text { experiences than those at late stages, after diagnoses were } \\
\text { received. They recognized that their experiences might change } \\
\text { as the syndrome progressed. }\end{array}$ & $\begin{array}{l}\text { A lot of people don't have such a positive journey as we're } \\
\text { having. Time will come... but right now... whatever comes, we'll } \\
\text { deal with it. (Care partner) }\end{array}$ \\
\hline $\begin{array}{l}\text { Peer and social sup- } \\
\text { port }\end{array}$ & $\begin{array}{l}\text { Both persons with dementia and care partners had almost } \\
\text { universally positive experiences with support provided through } \\
\text { avenues such as day programs, veterans associations, and } \\
\text { volunteer programs. Day programs served as respite for care } \\
\text { partners and social stimulus for persons with dementia. }\end{array}$ & $\begin{array}{l}\text { I understand that the other people in that group are going } \\
\text { through the same thing that l am... and I've always known that } \\
\text {... but it's comforting to hear it face to face instead of reading } \\
\text { about it. (Care partner) }\end{array}$ \\
\hline $\begin{array}{l}\text { Provider compassion } \\
\text { and professional- } \\
\text { ism }\end{array}$ & $\begin{array}{l}\text { Although several system issues were mentioned, people with } \\
\text { dementia and care partners commonly had positive feelings } \\
\text { about the individuals involved in their care. The compassion of } \\
\text { care providers was clear in descriptions of positive experi- }\end{array}$ & $\begin{array}{l}\text { Ithink it's a genuine compassion - that compassion may be borne } \\
\text { out of the professionalism. But it strikes me as something that } \\
\text { you don't find in everyone, so clearly these people chose this } \\
\text { profession because it suited who they are. (Care partner) }\end{array}$ \\
\hline
\end{tabular}

\begin{tabular}{ll}
\hline Strengths Identified by & Representatives from the Health Care Sector \\
\hline Strengths & Description \\
\hline Variety of services & $\begin{array}{l}\text { Diverse services are offered in the SW LHIN, allowing individuals } \\
\text { to have flexibility when deciding what aligns with their wants } \\
\text { and needs. Day programs have been a particularly valuable } \\
\text { service, and benefit persons with dementia and their care } \\
\text { partners. }\end{array}$
\end{tabular}

Early screening and There has been movement towards early screening and diagclear diagnosis nosis, which establishes links early on in the journey. This early intervention is aided by the integration of memory clinics.

Provider expertise, professionalism, and compassion
Local provider expertise is supplemented by empowering patients and their care partners to have a voice in the care process. Providers are dedicated to working with the persons with dementia, the care partners, and the dyadic unit.

\section{Verbatim Examples}

I think first and foremost we do have a variety of services available...for persons with dementia and their caregivers in multiple care settings. (Health care administrator)

There's more memory clinics now within the LHIN than there was, and it's a really good model to help particularly with early diagnosis and identification of patients who are at risk. (Family physician)

I think the professionals have a great deal of passion in helping families and emphasizing getting families the best service that they can. I think they spend a lot of time with caregivers, so they're not just looking at the person with dementia, but they look at the family unit and assess that there are caregivers struggling as well. (Social worker)

Technology Different technological resources are currently being used to help providers stay organized and connected. Technology is also being used to engage persons with dementia and their care partners, while keeping them mentally active and physically safe. Health care professionals illustrated the value of technology with specific examples.

We also do a note online so that it's actually in service. It comes up with the clinician notes that means that if the person does come into emerg, the emerg staff is alerted that they're being followed by the BSO [Behavioural Supports Ontario]. And we usually get notification whether from the floor or up in the long-term care home will call and ask us to follow up while they're in hospital. Then we try to do a smooth transition back to wherever they're from. (Behaviour therapist)

We also have areas of research and evaluation that are important, so that as we drive to improve services... the robust research and evaluation ensures that we're going in the right direction. (Geriatric specialist) whereas health care providers and administrators did not rank this as high (8.73).

\section{Data Synthesis and Strategic Framework}

Our project identified strategic priorities and produced a dementia strategy strategic framework. The five strategic priorities for the SW LHIN dementia strategy are (1) promoting patient centred-care, (2) improving care partner support, (3) supporting persons with dementia across the disease continuum (from diagnosis onward), (4) improving access to care, and (5) improving quality across the system of care. The framework visually encapsulates the strengths, needs, priorities, 
Table 5: System gaps and needs

\section{Gaps and Needs Identified by Persons with Dementia and their Care Partners}

\begin{tabular}{llc}
\hline Gaps and Needs & Description & Verbatim Examples \\
\hline $\begin{array}{l}\text { Integration and care } \\
\text { coordination }\end{array}$ & $\begin{array}{c}\text { Integration and coordination needs improvement in the areas of } \\
\text { provider-provider communication, patient-provider com- } \\
\text { munication, having a hub of care, collaboration, and team- } \\
\text { work. The system can be confusing and distuptions can be } \\
\text { significant stressors in the lives of people with dementia. }\end{array}$ & $\begin{array}{c}\text { A person with dementia described their confusion in under- } \\
\text { standing the system: "they've got the words that you don't } \\
\text { know what they are saying." }\end{array}$ \\
$\begin{array}{lll}\text { I mean you're constantly repeating the same thing to every } \\
\text { person that you see... you're not answering to every person } \\
\text { and why are they not looking at what someone has already } \\
\text { asked you before? Is it they're wanting a confirmation on } \\
\text { this? Or what? (Care partner) }\end{array}$
\end{tabular}

Training and education There is a gap in training in education for providers, patients and care partners, and the public. Provider skills, patient preparedness, and public awareness could benefit from improved education.

Care partner support Care partners felt responsible for their loved ones with dementia, and often found decision making difficult. The need to address care partner stress and exhaustion was clear in listening to their experiences.
I cannot reiterate enough that there's not enough training... I think that as time goes on it is an area where more training is going to be needed with all staff. Because more and more of this is coming. (Care partner)

Well I think the thing is that it's $24 / 7$ for the caregiver... I think they're beginning to realize that... I don't mean Alzheimer's, but other people are beginning to realize that the burnout, the exhaustion... when he was taken to the hospital the doctor said, 'Which one of you is the patient?' That's how ill I was at the time. (Care partner)
I think letting the staff know who this person is... And that conversation is important. I think that often... it's not anything that'll happen... There's not enough time for the [providers] to have enough time with them... It's really important that the staff know something about who that person was. (Care partner)

The woman in charge did not allow you to have contact with PSWs [Personal Support Worker] prior to booking... if I particularly liked this one person... I was not allowed to talk to her and say "[PSW], what would be the best time that would work for us?" She wanted me to go in, to phone in the times and not try to arrange it any other way. She would send who comes. (Care partner)

\section{Gaps and Needs Identified by Representatives from the Health Care Sector}

\begin{tabular}{ll}
\hline Gaps and Needs & Description \\
\hline $\begin{array}{l}\text { Integration, coordin- } \\
\text { ation and collabor- } \\
\text { ation }\end{array}$ & $\begin{array}{l}\text { There is an evident disconnect in the coordination and collab- } \\
\text { oration of care because of a siloed approach. Improved } \\
\text { collaboration or the introduction of a system navigator/care } \\
\text { coordinator role could help improve the streamlining of } \\
\text { processes. }\end{array}$
\end{tabular}

Care partner support Care partners experience a long and stressful journey, and many of them experience burnout. Their needs are varied and can change as they assist the individual with dementia along the continuum, requiring different supports at different stages.

\section{Verbatim Examples}

We are good at doing things within our current team but we haven't evolved to having clear kind of integrated or collaborative structures to help health care providers work together to make sure that we have the best quality of care for the most people. (Geriatric specialist)
The other part for the caregiver, too, is their own mental health, right, and so I think we speak to education for them, better communication skills, that are even skills around managing behaviours, but many of them are very high risk of developing depression, because of the burden of supporting somebody, and that can impact them at their workplace as well as, you know, in the community, so I don't know, I think there's a lot there in terms of what can we do (Geriatric Specialist)

\begin{tabular}{cc}
$\begin{array}{c}\text { Education and aware- } \\
\text { ness }\end{array}$ & $\begin{array}{c}\text { There is a need for more education to reduce the stigma and } \\
\text { improve the quality of care with partners within and external } \\
\text { to their immediate circle of care. }\end{array}$ \\
\hline $\begin{array}{c}\text { Lack of accessibility, } \\
\text { flexibility, and con- } \\
\text { sistency with services }\end{array}$ & $\begin{array}{r}\text { There are barriers that restrict access to services including long- } \\
\text { term care, end-of-life care, and respite. Primary limitations } \\
\text { include legislation, location, and consistency. The concept of } \\
\text { double dipping emerged as a constraint to service accessibility. }\end{array}$
\end{tabular}

I struggle with the stigma part, a little bit. But it's not like they've got a disease and we've got to stay away from them because it's contagious. (Health care administrator)

The legislation tells us that a client living in a long term care home cannot attend a community day program because it's seen as double dipping into the health care resources. (Health care administrator) 
Table 5: Continued

\begin{tabular}{|c|c|c|}
\hline \multicolumn{3}{|c|}{ Gaps and Needs Identified by Persons with Dementia and their Care Partners } \\
\hline Gaps and Needs & Description & Verbatim Examples \\
\hline $\begin{array}{l}\text { Managing emotional, } \\
\text { behavioural, and } \\
\text { functional changes }\end{array}$ & $\begin{array}{l}\text { As dementia progresses, individuals may develop mental health } \\
\text { or behavioural challenges. There are a limited number of } \\
\text { geriatric psychiatric resources, and sometimes persons with } \\
\text { dementia end up in the judicial system. }\end{array}$ & $\begin{array}{l}\text { So we can talk about, you know people have cognitive parts of } \\
\text { their dementia but if we don't give voice to those emotional, } \\
\text { behavioural, functional changes that are concurrent with } \\
\text { their cognitive changes, we miss sometimes the huge impact } \\
\text { that it's in fact having on the individual, their family, and the } \\
\text { health care system. (Geriatric specialist) }\end{array}$ \\
\hline $\begin{array}{l}\text { High case load and } \\
\text { shortage of staff }\end{array}$ & $\begin{array}{l}\text { The number of clients is increasing by over } 10 \% \text { each year, but } \\
\text { the number of staff remains stagnant. This problem raises a } \\
\text { concern for staff health and burnout. }\end{array}$ & $\begin{array}{l}\text { Each year we're seeing... probably } 300 \text { new caregivers and } \\
\text { people with dementia...the numbers are growing so much } \\
\text { that I worry about the capacity of out staff. I worry about } \\
\text { their health in looking after all of these people, because it's } \\
\text { just overwhelming, the volume. (Administrator) }\end{array}$ \\
\hline
\end{tabular}

Table 6: Priority ratings, overall and from each informant group

\begin{tabular}{|c|c|c|c|}
\hline Priorities $^{a}$ & Overall Rating & $\begin{array}{l}\text { Persons with Dementia/ } \\
\text { Care Partner Rating }\end{array}$ & $\begin{array}{l}\text { Provider/Admin. Rat- } \\
\text { ing }\end{array}$ \\
\hline Improve care partner support & 9.24 & 9.33 & 9.22 \\
\hline Improve access to care & 9.16 & 9.36 & 9.12 \\
\hline Improve quality across the system of dementia care & 9.10 & 9.50 & 9.00 \\
\hline Support persons with dementia across the continuum & 9.06 & 8.92 & 9.10 \\
\hline Provide coordinated and integrated care and system navigation support & 8.97 & 9.67 & 8.80 \\
\hline Promote flexibility of services & 8.97 & 9.08 & 8.94 \\
\hline Promote patient-centred care & 8.95 & 8.64 & 9.02 \\
\hline Educate the workforce & 8.73 & 9.42 & 8.55 \\
\hline Improve public awareness and support dementia-friendly communities & 8.52 & 9.17 & 8.37 \\
\hline Improve access to information and education for patients and care partners & 8.50 & 8.91 & 8.41 \\
\hline Commit to research and knowledge exchange & 8.42 & 9.17 & 8.24 \\
\hline Promote holistic health and wellness & 8.18 & 8.64 & 8.08 \\
\hline Integrate technology into support and management & 8.03 & 7.92 & 8.06 \\
\hline
\end{tabular}

Note. ${ }^{a}$ Objectives are listed in order of their overall rank.

and values that we identified through data collection and stakeholder engagement. A full copy of the dementia strategy, including actionable steps for each of the priorities, can be obtained by contacting the corresponding author.

\section{Strategic Framework: Whole Person, Whole Journey}

Person-centred values

The phrase "whole person, whole journey" was chosen to reflect principles of a holistic, person-centred perspective on the experience of dementia and a broad and integrated health system and community response. A strong body of international literature supports the value of patient and client-centred care, both for persons living with dementia (e.g., Kim \& Park, 2017), and staff (Barbosa, Sousa, Nolan, \& Figueiredo, 2015). The band across the top of Figure 1 presents a focus on personcentred care throughout the dementia journey. This reflects the need commonly cited by persons with dementia and their care partners: that those involved in care must have an in-depth knowledge of the individual. Persons living with dementia and their care partners felt that providers failed to address the unique individual living with dementia and tended to rely on statistics and test results to develop care plans. One care partner explained, "I do find that...they tend to depend more on numbers and the results of tests rather than taking the different personalities into the equation." An emphasis on person-centred care is crucial. The qualitative analysis suggests that care experiences can be greatly improved by a shift in provider attitudes and practice toward person-centred care.

\section{Drivers and Goals}

The drivers build on both existing strengths (e.g., patient engagement and compassion, increased research and evaluation) and some of the identified needs (e.g., increased education for the workforce). As one family physician noted, "There needs to be more education, because we have this tsunami that's hitting 
us." The drivers of engagement, education, research, and technology, although important in their own right, are catalysts for improvements to community and system support for persons with dementia and their care partners. Drivers for changes included (1) engagement of persons with dementia and caregivers in health care decision making and research; (2) education of persons with dementia, caregivers, providers, and the public, including but not limited to education on the disease and community supports, education on diagnosis and treatments, and broader educational efforts to reduce stigma; (3) a commitment to research and knowledge exchange; and (4) the integration of technology into both support and management. The goals are reflective of some of the highest ranked priorities, including improved access to care, including primary care; improved care coordination, including system navigation and better use of interprofessional teams and "care hubs"; and improved quality across the system of dementia care, including improved quality within primary care (e.g., more timely diagnoses), and greater community-based supports that would facilitating aging in place.

\section{Support systems, including care partners}

The key stakeholders identified in the framework include persons with dementia, their care partners, and care providers. Support for care partners was the highestranked priority amongst health care providers and was repeatedly cited in our interviews. In the interviews, support for care partners included emotional and mental health support, respite care, and information and system navigation supports. Care partners felt responsible for their loved ones with dementia, and often found decision making difficult. The need to address care partner stress and exhaustion was clear in listening to interviews with all participant groups: A health care provider noted, "The caregivers give $100 \%$ and they care and love and they'll do anything to help their spouse, or mother, or dad... so they're giving $100 \%$ and they just collapse." Health care workers also recognized the long and stressful journey faced by care partners, and the lack of individualized supports, and consequentially the associated burnout. A social worker said: "You just see these caregivers come in, and they are exhausted, and they are tired... and they are told there's just one more thing they need to do, or one more agency that needs to be involved... and they are tired! And they are grieving."

This social worker's quote encapsulates the overarching objective of this dementia strategy development process: to support persons with dementia, and their caregivers and health care providers, because dementia can be exhausting, demanding, and complex to navigate for all parties involved.

\section{Discussion}

To create a dementia strategy that is person-centred, client and family-centred, and informed by the perspectives of health care providers, it was essential that we meaningfully engaged with all of these groups. We did this by understanding the lived experience of persons with dementia and their care partners; eliciting the professional input of health care providers and policy makers; and asking all informant groups to identify their priorities. One strength of our work is that the strategy was derived from interviews and surveys with a range of care partners and persons living with dementia from throughout the health region. Our team logged hundreds of kilometers traversing a large region to meet persons with dementia in their homes. Interviewing in private homes is less onerous for the persons with dementia and their care partners and may also give the participants a deeper sense of comfort (Elwood \& Martin, 2000), especially for those experiencing cognitive decline.

The result of this immersive stakeholder engagement was a strategic framework that integrates the strengths, gaps, needs, priorities, and values identified by the participant groups. The overarching value that guides the "Whole Person, Whole Journey" framework is person-centred care, and also family-centred care. Person-centred and family-centred care means that persons with dementia, and their care partners, have relationships with their care providers, and that they are involved in decisions made about their care (Kitson, Marshall, Bassett, \& Zeitz, 2013). Person-centred care has been a focus of many provincial and national dementia strategies (Edick et al., 2017), yet few organizations have endeavoured to examine the lived experiences of persons with dementia and their care partners as they receive person-centred care (Edvardsson, Fetherstonhaugh, \& Nay, 2010).

Although all of the individuals in the framework require adequate support, results emphasized the need for increased care partner support. In Canada, home and community support is limited both in terms of what is eligible for publicly funded support (Martin-Matthews, Sims-Gould, \& Tong, 2012), and further limitations because of geography and access to care, particularly in remote and rural areas. For persons with dementia who are community dwelling, the bulk of their care and the associated burden and stress are relegated to care partners, family members, and friends (Feldman \& Estabrooks, 2017). In the SW LHIN, 40 per cent of care partners reported feeling stressed or overwhelmed (South West Local Health Integration Network, 2014), and this is consistent with national-level surveys on informal care partner burden and stress (Canadian Institute for Health Information, 2010). It was essential to include care partner support in the centre of the framework. 
The "Whole Person, Whole Journey" strategic framework is situated within dementia- friendly communities, as noted at the bottom of Figure 1. Creating dementia-friendly communities and cities is, for the most part, outside the scope and mandate of regional health authorities. This is where provincial- and national-level dementia strategies take on an important role. Regional dementia strategies must occur within a context in which other levels of government are simultaneously working on broader community and nationwide issues.

We began developing the SW LHIN dementia strategy in 2015, whereas the province of Ontario funded a provincial dementia strategy in 2017 (Alzheimer Society of Canada, 2018b). In 2017, Canada also became the 30th country to launch a national dementia strategy (Alzheimer Society of Canada, 2018a). This became law in Canada, through the introduction of Bill C-233, "An Act respecting a national strategy for Alzheimer's disease and other dementias". The federal strategy focuses on national-level objectives, national-level organizations, investments in research, and coordinating and sharing best care practices across the provinces and territories. The National Dementia Strategy, through work with the Public Health Agency of Canada and the World Health Organization, emphasizes the creation of and support for age-friendly and dementia-friendly communities (Government of Canada, 2019; Philpott, 2017). The National Dementia Strategy is also working federally on some of the "drivers" identified in our framework, including supporting world-class dementia research (e.g., the Canadian Institutes of Health Research Dementia Research Strategy [Canadian Institutes of Health Research, 2016b]) and advances in technology. The National Dementia Strategy (Government of Canada, 2019; Philpott, 2017) also supports some of the "goals" in the "Whole Person, Whole Journey" framework, including improved access (e.g., through large investments in home and community care) and awareness (e.g., through national and international awareness days). The national strategy also echoes our call for increased support for care partners, with national-level policy focused on employee benefits, care partner tax credits, and intended changes to the labour code (Government of Canada, 2019; Philpott, 2017).

The Ontario provincial dementia strategy focuses on six issues: support for persons with dementia, access to dementia services, coordinated care, support for care partners, a well-trained dementia workforce, and increasing awareness/reducing stigma (Ontario, 2016). Both the provincial and "Whole Person, Whole Journey" strategies focus on access to care, support for individuals with dementia and their care partners, and improving the quality of care. The SW LHIN has a dementia strategy that is complementary to the provincial and national strategies, but administrators can also be confident that the regional strategy is reflective of their local needs, and the perspectives of their staff, community partners, persons with dementia, and their care partners.

\section{Considerations for the Development of a Regional Dementia Strategy}

Our research provides insights for other regional organizations seeking to create their own dementia strategies, even in a context where federal, provincial, or other higher-level strategies exist. First, it was vital to develop and meaningfully engage with community representatives to guide the entire process. Recruitment, and eventually the successful implementation and uptake of this research, would not have been possible without the advisory boards. Second, a qualitative approach allowed us to examine the lived experiences of persons with dementia and their care partners; their lived experiences included not just the biomedical and physiological dimensions of dementia, but also sociocultural dimensions (e.g., communication, culture of care, relationships) (Downs, 2000; Mead, Eckert, Zimmerman, \& Schumacher, 2005). Our university research team has expertise in qualitative research with older adults and health care providers, and a universityhealth care partnership was ideal for this type of strategy-development work. Finally, the implementation of an online priority-setting survey allowed us to distill key findings, highlight divergent opinions, and identify which priorities to emphasize in the final dementia strategy and framework. Again, this was an opportunity to engage with persons with dementia and their care partners, to invoke their perspectives in the final strategy. Given the extensive nature of our data collection, the "Whole Person, Whole Journey" framework may serve as a springboard for other organizations seeking to create their own dementia strategy.

\section{Limitations}

The findings from this study are specific to the needs and priorities of the SW LHIN, as intended; however, other organizations seeking to develop a regionspecific, locally driven dementia strategy may learn from the processes we implemented and the final strategic framework. Also, although our group made considerable efforts to gain the perspectives of persons living with dementia, we believe that our work would have benefited from additional involvement of these persons. Our work is also limited because we recruited through the Alzheimer's Society, which indicates that our participants were individuals who were already linked, to some degree, to community supports and services. In addition, our sample principally consisted 
of women care partners and men with dementia. This is reflective of the typical care partner profile, which tends to be middle-aged and older women (Brodaty \& Donkin, 2009), but future research should endeavour to capture the experiences of men care partners and women living with dementia. This is especially important, as a much higher percentage of women than men are living with dementia (Canadian Institutes of Health Research, 2013). Also, our online priority-setting survey may have privileged participants with Internet access; a mail-out strategy may have facilitated greater participation among care partners and persons with dementia. Finally, we did not collect socio-demographic (e.g., ethnicity) or socio-economic information on participants. Although we made efforts to reach a balance of urban and rural participants, we know that people who are visible minorities, and persons with low socioeconomic status are under-represented in clinical research (Farmer, Jackson, Camacho, \& Hall, 2007). We also did not specifically recruit Indigenous persons for this work. Meaningful engagement with Indigenous communities regarding dementia care requires dedicated and culturally appropriate efforts, as has been demonstrated by Webkamigad, Cote-Meek, Pianosi, and Jacklin (2019), and Jacklin and Walker (2019).

An additional limitation of our strategy is that, like most dementia strategies in Canada, it is firmly rooted in the realm of "health care". Pot and Petrea (2013) note that dementia strategies are created to ensure that "health and social care systems are adequately structured and funded.... [to support] people living with dementia" (p. 5, emphasis ours). In Canada, the formal health and social care systems operate separately from one another (Government of Canada, 2018), with individuals living with dementia left to navigate these two disparate systems. Future dementia strategies, in particular at the provincial and national levels, must look for opportunities to bridge the social care and health care systems for persons with dementia and their families.

\section{Conclusion}

Our research allowed us to develop a dementia strategy firmly rooted in the lived experiences and priorities of persons with dementia, their care partners, and the staff and administrators charged with providing dementia care in the SW LHIN. A particular strength of our approach was meaningful engagement with persons with dementia, care partners, and health care providers throughout the study (Canadian Institutes of Health Research, 2016a; Domecq et al., 2014). Our approach and resultant dementia strategy, including the "Whole Person Whole Journey" framework, will be of use to local and regional organizations endeavouring to implement or develop a dementia strategy

\section{Supplementary Materials}

To view supplementary material for this article, please visit http:/ / dx.doi.org/10.1017/S071498082000015X.

\section{References}

Alzheimer Society of Canada. (2010). Rising tide: The impact of dementia on Canadian society 2010. Retrieved 18 May 2020 from https://alzheimer.ca/sites/default/files/files/ national/advocacy/asc_rising_tide_full_report_e.pdf

Alzheimer Society of Canada. (2018a). Canada's national dementia strategy. Retrieved 18 May 2020 from http:/ / alzheimer.ca/en/Home/Get-involved/Advocacy/Nationaldementia-strategy

Alzheimer's Society of Canada. (2018b). Ontario achieves a fully funded dementia strategy! Retrieved on May 18, 2020 from http://alzheimersocietyblog.ca/ontarioachieves-fully-funded-dementia-strategy /

Alzheimer's Society of Canada. (2019). Your guide to Canada's national dementia strategy. Retrieved 18 May 2020 from https:/ / alzheimer.ca/en/Home/Get-involved/Advocacy / National-dementia-strategy-guide\#provinces

Barbosa, A., Sousa, L., Nolan, M., \& Figueiredo, D. (2015). Effects of person-centered care approaches to dementia care on staff: A systematic review. American Journal of Alzheimer's Disease E Other Dementias ${ }^{\circledR}, 30(8), 713-722$.

Bradley, E. H., Curry, L. A., \& Devers, K. J. (2007). Qualitative data analysis for health services research: Developing taxonomy, themes, and theory. Health Services Research, 42(4), 1758-1772.

Brodaty, H., \& Donkin, M. (2009). Family caregivers of people with dementia. Dialogues in Clinical Neuroscience, 11(2), 217-228.

Bronfenbrenner, U. (1977). Toward an experimental ecology of human development. American Psychologist, 32(7), 513-531.

Burns, A. (2010). Editorial: Special Issue: The challenges of dementia: An international perspective. International Journal of Geriatric Psychiatry, 25(9), 875.

Canadian Academy of Health Science . (2019). Improving the quality of life and care of persons living with dementia and their caregivers. Canadian Academy of Health Sciences' assessment of dementia care in Canada. Retrieved 18 May 2020 from https://www.cahsacss.ca/wp-content/uploads/2019/01/Report.pdf

Canadian Institute for Health Information. (2010). Supporting informal caregivers: The heart of home care. Retrieved 18 May 2020 from https: / / secure.cihi.ca/free_products / Caregiver_Distress_AIB_2010_EN.pdf

Canadian Institutes of Health Research. (2013). Alzheimer's research in Canada. Retrieved 18 May 2020, from https:/ / alzheimer.ca/sites/default/files/images/national/ get $\% 20$ involved/raise\%20your\%20voice/cihr_alzheimer_ infographic_e.pdf 
Canadian Institutes of Health Research. (2016a). Capacity development framework. Retrieved 18 May 2020, from http:/ / www.cihr-irsc.gc.ca/e/49307.html

Canadian Institutes of Health Research. (2016b). Components of the CIHR Dementia Strategy. Retrieved 18 May 2020 from https:/ / cihr-irsc.gc.ca/e/43758.html

Charmaz, K. (2015). Teaching theory construction with initial grounded theory tools: A reflection on lessons and learning. Qualitative Health Research, 25(12), 1610-1622.

City of London. (2019). Immigration, ethno-cultural diversity, and language. Retrieved 18 May 2020 from https:// www.london.ca/About-London/community-statistics/ population-characteristics/Pages/Immigrant-Population. aspx

Constantinescu, A., Li, H., Yu, J., Hoggard, C., \& HolroydLeduc, J. (2018). Exploring rural family physicians' challenges in providing dementia care: A qualitative study. Canadian Journal on Aging/La Revue Canadienne Du Vieillissement, 37(4), 390-399.

Creswell, J. W. (2007). Qualitative inquiry \& research design: Choosing among five approaches (2nd ed.). Thousand Oaks, CA: Sage.

Cutcliffe, J. R., \& McKenna, H. P. (2004). Expert qualitative researchers and the use of audit trails. Journal of Advanced Nursing, 45(2), 126-133.

Dewing, J., \& Dijk, S. (2016). What is the current state of care for older people with dementia in general hospitals? A literature review. Dementia, 15(1), 106-124.

Domecq, J. P., Prutsky, G., Elraiyah, T., Wang, Z., Nabhan, M., Shippee, N., et al. (2014). Patient engagement in research: A systematic review. BMC Health Services Research, 14(1), 89.

Downs, M. (2000). Dementia in a socio-cultural context: An idea whose time has come. Ageing $\mathcal{E}$ Society, 20(3), 369-375.

Edick, C., Holland, N., Ashbourne, J., Elliott, J., \& Stolee, P. (2017). A review of Canadian and international dementia strategies. Healthcare Management Forum, 30(1), 32-39.

Edvardsson, D., Fetherstonhaugh, D., \& Nay, R. (2010). Promoting a continuation of self and normality: Personcentred care as described by people with dementia, their family members and aged care staff. Journal of Clinical Nursing, 19(17-18), 2611-2618.

Elwood, S. A., \& Martin, D. G. (2000). "Placing" interviews: Location and scales of power in qualitative research. The Professional Geographer, 52(4), 649-657.

Emerson, R. M., Fretz, R. I., \& Shaw, L. L. (2011). Writing ethnographic fieldnotes. Chicago: University of Chicago Press.

Farmer, D. F., Jackson, S. A., Camacho, F., \& Hall, M. A. (2007). Attitudes of African American and low socioeconomic status white women toward medical research. Journal of Health Care for the Poor and Underserved, 18(1), 85-99.
Feldman, H. H., \& Estabrooks, C. A. (2017). The Canadian dementia challenge: Ensuring optimal care and services for those at risk or with dementia throughout the country. Canadian Journal of Public Health, 108(1), 95-97.

Fortinsky, R. H., \& Downs, M. (2014). Optimizing personcentered transitions in the dementia journey: A comparison of national dementia strategies. Health Affairs, 33(4), 566-573.

The Geriatric Health Systems Research Group. (2016). Whole Person, Whole Journey. Waterloo, ON.

Government of Canada. (2018). Canada's health care system. Retrieved 18 May 2020 from https:/ / www.canada.ca/ en/health-canada/services / canada-health-care-system.html

Government of Canada. (2019). A dementia strategy for Canada: Together we aspire. Retrieved 18 May 2020, from https:/ / www.canada.ca/en/public-health/services/publications/ diseases-conditions/dementia-strategy.html

Guest, G., \& MacQueen, K. M. (2008). Handbook for team-based qualitative research. Lanham, MD: Altamira Press.

Guillette, M., Lanneville, D., Couturier, Y., Tannouche Bannani, S., Thiam, Y., Belzile, L., et al. (2018). Literature review: Alzheimer's disease policies in OECD countries. Quebec, Canada: Universite de Sherbrooke. Retrieved 17 May 2020 from https://savoirs.usherbrooke.ca/bitstream/ handle/11143/14189/Literature\%20review\%20of\% 20Alzheimers \%20policies $\% 20 \% 282000-2018 \% 29$.pdf? sequence $=1 \&$ is Allowed $=\mathrm{y}$

Jaccard, J., \& Jacoby, J. (2010). Theory construction and modelbuilding skills: A practical guide for social scientists. New York: Guilford.

Jacklin, K., \& Walker, J. (2019). Cultural understandings of dementia in indigenous peoples: A qualitative evidence synthesis. Canadian Journal on Aging/La Revue Canadienne Du Vieillissement, 39(2), 220-234. https://doi.org/ 10.1017/S071498081900028X

Johnson, B. H., Abraham, M. R., \& Shelton, T. L. (2009). Patientand family-centered care: Partnerships for quality and safety. North Carolina Medical Journal, 70(2), 125-130.

Kim, S. K., \& Park, M. (2017). Effectiveness of person-centered care on people with dementia: A systematic review and meta-analysis. Clinical Interventions in Aging, 12(1), 381-397.

Kim, S. Y. (2011). The ethics of informed consent in Alzheimer disease research. Nature Reviews Neurology, 7(7), 410-414.

Kitson, A., Marshall, A., Bassett, K., \& Zeitz, K. (2013). What are the core elements of patient-centred care? A narrative review and synthesis of the literature from health policy, medicine and nursing. Journal of Advanced Nursing, 69(1), 4-15.

Martin-Matthews, A., Sims-Gould, J., \& Tong, C. E. (2012). Canada's complex and fractionalized home care context: Perspectives of workers, elderly clients, family carers, and home care managers. Canadian Review of Social Policy, 2012(68/69), 55-74. 
Mead, L. C., Eckert, J. K., Zimmerman, S., \& Schumacher, J. G. (2005). Sociocultural aspects of transitions from assisted living for residents with dementia. The Gerontologist, 45 (Suppl. 1), 115-123.

Morgan, D. (2018). Addendum of commissioned reports. Appendix A: Rural dementia care. Ottawa: Canadian Academy of Health Sciences.

Morgan, D., Crossley, M., Kirk, A., McBain, L., Stewart, N., D'Arcy, C., et al. (2011). Evaluation of telehealth for preclinic assessment and follow-up in an interprofessional rural and remote memory clinic. Journal of Applied Gerontology, 30(3), 304-331.

Morgan, D., Innes, A., \& Kosteniuk, J. (2011). Dementia care in rural and remote settings: A systematic review of formal or paid care. Maturitas, 68(1), 17-33.

Morse, J. (2015). Data were saturated. Qualitative Health Research, 25(5), 587-588.

Nakanishi, M., Nakashima, T., Shindo, Y., Miyamoto, Y., Gove, D., Radbruch, L., et al. (2015). An evaluation of palliative care contents in national dementia strategies in reference to the European Association for Palliative Care white paper. International Psychogeriatrics, 27(9), 1551-1561.

Ontario. (2016). Developing Ontario's dementia strategy: Discussion paper 2016. Retrieved 17 May 2020 from https: / / www.ontario.ca/page/developing-ontariosdementia-strategy-discussion-paper

Patton, M. Q. (2002). Qualitative research E evaluation methods (3rd ed.). Thousand Oaks, CA: Sage.

Philpott, J. (2017). The government response to the Sixth Report of the Standing Senate Committee on Social Affairs, Science and Technology, entitled Dementia in Canada: A National Strategy for Dementia-friendly Communities which was tabled on November 15, 2016. Ottawa: Minister of Health.

Pot, A. M., \& Petrea, I. (2013). Improving dementia care worldwide. Ideas and advise on developing and implementing a national dementia plan. Retrieved 18 May 2020 from https:/ /www.alz.co.uk/sites/default/ files/pdfs/global-dementia-plan-report-ENGLISH.pdf

Richards, L., \& Morse, J. (2007). Readme first for a user's guide to qualitative methods. Thousand Oaks, CA: Sage.
Rockwood, K., \& Keren, R. (2010). Dementia services in Canada. International Journal of Geriatric Psychiatry, 25 (9), 876-880.

Saldaña, J. (2016). The coding manual for qualitative researchers (3rd ed.). Thousand Oaks, CA: Sage.

Silva, A. L., Teixeira, H. J., Teixeira, M. J. C., \& Freitas, S. (2013). The needs of informal caregivers of elderly people living at home: An integrative review. Scandinavian Journal of Caring Sciences, 27(4), 792-803.

South West Local Health Integration Network. (2014). South west behavioural supports Ontario data elements 2013-2014. Unpublished document provided by Dr. Iris Gutmanis.

South West Local Health Integration Network. (2018). Geography and communities 2018. Retrieved on May 18, 2020, from http:/ / www.southwestlhin.on.ca/aboutus/facts.aspx

South West Local Health Integration Network. (2019). Engaging our communities. Retrieved 18 May 2020 from http:// www.southwestlhin.on.ca/communityengagement.aspx

Steelman, E., De Casterlé, B. D., Godderis, J., \& Grypdonck, M. (2006). Living with early-stage dementia: A review of qualitative studies. Journal of Advanced Nursing, 54(6), 722-738.

Tracy, S. J. (2010). Qualitative quality: Eight "big-tent" criteria for excellent qualitative research. Qualitative Inquiry, 16 (10), 837-851.

von der Gracht, H. A. (2012). Consensus measurement in Delphi studies: Review and implications for future quality assurance. Technological Forecasting and Social Change, 79(8), 1525-1536.

Webkamigad, S., Cote-Meek, S., Pianosi, B., \& Jacklin, K. (2019). Exploring the appropriateness of culturally safe dementia information with Indigenous people in an urban northern Ontario community. Canadian Journal on Aging/La Revue Canadienne Du Vieillissement, 4, 1-12. https: / / doi.org/10.1017/S0714980819000606

World Health Organization. (2017). Global action plan on the public health response to dementia 2017-2025. WHO Document Production Services. Retrieved 18 May 2020 from https:/ / www.who.int/mental_health/neurology / dementia/action_plan_2017_2025/en/ 